\title{
Mortality and cancer morbidity of production workers in the United Kingdom flexible polyurethane foam industry
}

Tom Sorahan, Debbie Pope

\begin{abstract}
Objective-To describe cause specific mortality and site specific cancer morbidity among workers employed in factories that produce polyurethane foams, and to determine if any part of the experience may be due to occupation, and in particular to exposure to diisocyanates.

Design-Historical prospective cohort study.

Setting-11 factories in England and Wales.

Subjects -8288 male and female production employees with some employment in the period 1958-79, and with a minimum period of employment of six months.
\end{abstract}

Main outcome measures-Observed and expected numbers of deaths for the period 1958-88, and corresponding figures for cancer registrations for the period $1971-86$.

Results-Compared with the general population of England and Wales, standardised mortality ratios (SMRs) for all causes and all neoplasms were 97 (observed deaths (Obs) 816) and 88 (Obs 221) respectively. Statistically significant excesses were found among women for cancer of the pancreas (expected deaths (Exp) 2-2, Obs 6, SMR 271, 95\% CI 100-595) and cancer of the lung (Exp 9.1, Obs 16, SMR 176, 95\% CI 100-285). Similar excesses were not found among male employees, and the SMRs for cancers of the lung and pancreas among the total study population were 100 (Obs 81) and 136 (Obs 14) respectively. Overall incidence of cancer was also below expectation (SRR 94, Obs 277), although statistically significant excesses among women were found for cancers of the larynx and kidney, based on three and four cases respectively. Incident cancers of the

Cancer Epidemiology Research Unit, Department of Public Health and Epidemiology, University of Birmingham, Edgbaston, Birmingham B15 2TJ

T Sorahan, D Pope lung and pancreas among women were also in excess, although these findings were not independent of the findings for mortality. Poisson regression did not indicate that ever having been employed in jobs attracting either higher or lower exposure to isocyanates was a risk factor for the mentioned cancers. A nested case-control design was used to investigate any associations with nine other occupational exposures. No statistically significant association was found.

Conclusions-In general, cancer rates in this population were lower than those for the general population. All increased cancer rates among women occurred at sites of cancer known to be related to cigarette smoking, and these excesses are probably due to a combination of cigarette smoking, chance, and factors unrelated to the industry under study.

(British Journal of Industrial Medicine 1993;50:528-536)

Organic isocyanates are chemicals characterised by the general chemical formula $\mathrm{R}(\mathrm{NCO}) \mathrm{x}$. The most important of these are toluene diisocyanate (TDI) and 4,4'-diisocyanatodiphenylmethane (MDI).

Toluene diisocyanate has a wide variety of industrial applications, and its most important is in the production of polyurethane flexible foam, most of which is used for cushioning and mattresses in the furniture industry, and for seating in the motor industry; MDI also has many applications, including the manufacture of polyisocyanurate rigid foams and polyurethane rigid and flexible foams, elastomers, and surface coatings.

Use of TDI in the United Kingdom flexible foam industry has been fairly constant over the past 15 years at some 20000 tonnes per annum; MDI was first introduced into the United Kingdom flexible foam industry in the early 1970s in small quantities. Since then its use has slowly increased to about 1000 tonnes per annum (5\% of TDI usage).

The vapour pressure of TDI at $20^{\circ} \mathrm{C}$ is $2.5 \times 10^{-2} \mathrm{mbar}$, which is much lower than that of water. Exposure can occur in its manufacture, han- 
dling, and use. The extent of exposure to workers in TDI production is limited. Production plants are designed for almost complete containment and are manned by few workers. The compound is normally transported in tankers and discharged into bulk storage, and here again exposure is limited. Workers engaged in the production of flexible polyurethane foams have a greater potential for exposure. Such workers may also be exposed to other chemicals, notably tertiary aliphatic amines used as catalysts, and chlorofluorocarbons or methylene chloride used as blowing agents. ${ }^{1}$

The vapour pressure of $\mathrm{MDI}$ is much lower than that of TDI, and potential exposure of workers to the vapour is significant only when $\mathrm{MDI}$ is used at high temperatures or in confined spaces. Higher exposure may occur when MDI is produced as a respirable aerosol, as can occur in spray applications. ${ }^{1}$

In 1983 the Health and Safety Executive (HSE) introduced a new concept in occupational exposure limits. For isocyanates the control limits were set in terms of concentration of total airborne isocyanate (-NCO) groups in the workplace, irrespective of the chemical species to which the NCO groups were attached. The concentrations introduced, and the equivalent concentrations for diisocyanates (in parenthesis) are:

eight hour TWA $\quad 0.02 \mathrm{mg}(-\mathrm{NCO}) / \mathrm{m}^{3} \quad(5 \mathrm{ppb})$

10 minute TWA $\quad 0.07 \mathrm{mg}(-\mathrm{NCO}) / \mathrm{m}^{3}(20 \mathrm{ppb})$

TWA $=$ time weighted average.

The second figure is equivalent to the first HSE exposure limit, expressed as a ceiling concentration level (former American Conference of Government Industrial Hygienists Threshold Limit Values) and introduced in 1965. Before 1965 the control limit for MDI or TDI was $0.05 \mathrm{ppm}$, introduced in the late 1950s. Some workers will have been exposed to levels above the control limits because of spillages, occasions when extraction has been inadequate, and risk taking by workers.

Occupational exposure to TDI at concentrations above the current occupational exposure limit has produced irritation of the upper and lower respiratory tract, sensitisation, and decrements in lung function..$^{2-4}$ The primary toxic effects of $\mathrm{MDI}$ are also on the respiratory system. Vapour aerosol and dust of MDI at concentrations well above the current occupational limit will irritate the nose, throat, lungs, and eyes and MDI can cause respiratory sensitisation in susceptible subjects. ${ }^{5}$

The study reported here is the first survey to investigate mortality and cancer incidence among workers exposed to TDI.

\section{Materials}

Study subjects are all the 8288 male and female employees from 11 participating factories in England and Wales, with a minimum period of employment of six months and with some employment in the period 1 January 1958 to 31 December 1979. (Workforce employees are here defined as all employees working in the factory environment and only clerical staff and management are excluded.) Participating factories were all those member companies of the British Rubber Manufacturers' Associations's polyurethane foam group that had commenced foaming before 1980. It was known from the outset that some of the factories did not have complete personnel records for their earlier years of manufacturing flexible polyurethane foams, and for these factories study subjects are members of either an entry cohort relating to those first employed in the period for which complete personnel records were available, or a survivor population relating to those first employed before the date from which complete personnel records were available and still in employment on that date.

Data collectors visited the factories to transcribe data from personnel files on to the study proforma. Data comprised identifying particulars and detailed job histories while employed at the participating factories. Job descriptions (job title and area of work) were transcribed from the personnel records; coding or classification of jobs was carried out later.

The National Health Service Central Register (NHSCR) provided information on the vital status of each worker on the closing date of the survey, 31 December 1988 (table 1). (For those workers who were classified as no trace at the NHSCR, details were sent to the offices of the Department of Social Security for tracing by means of national insurance numbers.) For those subjects who had died, a death certificate was obtained with the underlying cause of death coded to the 9th revision of the International Classification of Diseases (ICD -9). The NHSCR also supplied details of embarkations and cancer registrations (incident cancers) for the period 1971 onwards.

A job dictionary for each factory was prepared from the individual job histories. Factory 3 had 1756 entries in its job dictionary. These job dictionaries were supplied to an occupational hygienist familiar with the industry so that each entry could be classified in terms of its likely exposure to isocyanates (a higher, b lower, c minimal/zero, d unclassifiable). The classification was based largely on the occupational hygiene data available from the Medical Research Council isocyanate study ${ }^{6}$ over the period 1978-86, together with local information on changes that occurred before 1978. As a guide in setting up the classification, jobs were allocated to the higher band if 1978-86 isocyanate exposure in these jobs (eight hour TWA) was greater than $4 \mathrm{ppb}$, or if excursions above $10 \mathrm{ppb}$ occurred on most days; jobs were allocated to the lower band if $1978-86$ isocya- 
Table 1 Vital status at end of survey (31 December 1988)

\begin{tabular}{lrr}
\hline & \multicolumn{2}{c}{$N o(\%)$} \\
\hline Traced alive at NHSCR & 6823 & $(82 \cdot 3)$ \\
Traced alive at DSS & 350 & $(4 \cdot 2)$ \\
Emigrated & 134 & $(1 \cdot 6)$ \\
Deceased (with death certificate) & 803 & $(9 \cdot 7)$ \\
Deceased (no death certificate) & 20 & $(0 \cdot 2)$ \\
No trace & 158 & $(1 \cdot 9)$ \\
Total & 8288 & $(100.0)$ \\
\hline
\end{tabular}

${ }^{\star}$ Includes 38 employees still to be traced at NHSCR.

nate exposure (eight hour TWA) was 1.5 to $4 \mathrm{ppb}$, or if occasional excursions above $5 \mathrm{ppb}$ occurred; jobs were allocated to the minimal/zero band if 1978-86 exposure to isocyanate was less than $1.5 \mathrm{ppb}$ (eight hour TWA), and no exposures greater than $5 \mathrm{ppb}$ occurred. The values given here to define the limits of each band were selected on the basis of the best information currently available. Numbers of entries coded a, b, c, and d were 189, 701, 3628, and 94 respectively. The job dictionary entries and exposure assessments were then cross referenced with individual job histories to produce a computer file of exposure histories suitable for statistical analysis. At the end of follow up, the number of employees with an ever higher exposure assessment was 403 . Corresponding numbers for ever lower but never higher and always minimal/zero or unclassifiable were 1447 and 6438 respectively.

\section{Methods}

\section{EXTERNAL STANDARD}

Expected numbers of cause specific deaths (and cancer registrations) were calculated by applying quinary quinquennial rates for England and Wales to the person years at risk (PYR) generated by the data. A worker enters the PYR either at the end of the six month minimum employment period or the date at which records for all new employees became avail- able, whichever was later. A worker leaves the PYR at the end of the survey, date of death, date of embarkation, or the date of lost to follow up, whichever was the earlier. Computations were performed using the PERSONYEARS computer program. No contributions were made to observed or expected numbers beyond the age of 85 years.

The date at which records for all new employees became available had to be established for each factory. Two estimates were available; one supplied by the personnel department and one indicated by the data (comparison of frequency distributions for year of commencing employment and year of leaving employment). For example, for factory 1 , data were available for only two employees who left employment in the period 1958-76, which would suggest incomplete data for this period. A respectable number of records was available for leavers in the years 1977, 1978, and 1979. These data would suggest, then, that complete records are available for the period 1977 onwards. Table 2 gives the delineation of survivor populations and entry cohorts by year of commencing employment for each factory.

Standardised mortality ratios (SMRs) were calculated as the ratio of observed to expected numbers of deaths expressed as a percentage. Where significance tests have been carried out, two tailed tests are used.

\section{INTERNAL STANDARD: POISSON REGRESSION}

Six variables were considered to have the potential for influencing mortality within the cohort: sex, attained age (age at follow up or age at death), calendar year, type of cohort (entry cohort or survivor population), period of follow up in years from first employment, and level of exposure to isocyanates. In the analyses these are not treated as continuous variables, but rather each variable is categorised into a number of levels.

The variable, exposure to isocyanates, has three levels: ever employed in an a job (higher), ever

Table 2 Definition of factory cohorts and size of study population

\begin{tabular}{|c|c|c|c|c|c|}
\hline \multirow[b]{2}{*}{ Factory } & \multicolumn{2}{|c|}{ Year of commencing employment } & \multicolumn{3}{|c|}{ Study population } \\
\hline & Survivor population & Entry cohort & Men & Women & Total \\
\hline 1 & $1950-76$ & $1977-79$ & 456 & 129 & 585 \\
\hline 2 & $1971-77$ & $1978-79$ & 120 & 2 & 122 \\
\hline 3 & $1949-63$ & $1964-79$ & 2401 & 1349 & 3750 \\
\hline 4 & $1926-57$ & $1958-79$ & 758 & 226 & 984 \\
\hline 5 & $1935-69$ & $1970-79$ & 925 & 178 & 1103 \\
\hline 6 & $1932-67$ & $1968-79$ & 325 & 175 & 500 \\
\hline 7 & $1960-71$ & $1972-79$ & 156 & 0 & 156 \\
\hline 8 & $1960-75$ & $1976-79$ & 98 & 296 & 394 \\
\hline 9 & $1956-71$ & $1972-79$ & 289 & 19 & 308 \\
\hline 10 & $1959-75$ & $1976-79$ & 84 & 55 & 139 \\
\hline \multirow[t]{2}{*}{11} & $1959-71$ & $1972-79$ & 212 & 35 & 247 \\
\hline & & & 5824 & 2465 & 8288 \\
\hline
\end{tabular}


employed in a b job (lower), and never employed in either $a$ or $b$ jobs (always minimal/zero or unclassifiable). In general, employees do not enter their final exposure category on entry into the industry, and the analysis allows, therefore, for subjects to contribute PYR to two or all three of the exposure categories as and when job changes occur that involve a change in exposure state. An employee may move from an ever lower exposure category to an ever higher category but not the opposite. Numbers of deaths in the exposed categories were considered too small for duration of exposure to be considered.

A suitable TRANS subroutine was written for the PERSONYEARS computer program to provide both PYR and numbers of death for causes of interest for all combinations of all levels of the six previously mentioned variables. The output developed by this program can be read directly by the GLIM computer program, which carries out the statistical modelling. The purpose of the modelling is to establish whether the mortality experienced by the study cohort, and in particular the mortality experienced by the different exposure groups, can be described easily in terms of variables such as sex, attained age, and calendar year (covariates), or whether the inclusion of the exposure variable makes a statistically significant contribution to the ability of the overall model to describe the data.
In Poisson regression, the observed deaths are treated as Poisson variables and the death rates are modelled on a logarithmic scale as a function of the explanatory variables (covariates and the exposure variable). ${ }^{7}$

GLIM fits the model by choosing as estimates of the parameters, those values which minimise the discrepancy between the observed numbers of deaths (numerators of the death rates) and the theoretical (or fitted) values. In GLIM, this discrepancy is known as the deviance. The improvement in the fit of the model to the data resulting from addition of terms to the model is assessed by a likelihood ratio test based on the change in deviance between the two models. This change is distributed roughly as a $\chi^{2}$ statistic, with degrees of freedom equal to the number of terms added to the model.

\section{INTERNAL STANDARD: CONDITIONAL LOGISTIC} REGRESSION

Evidence of occupational risks arising from occupational exposures other than exposure to isocyanate was sought by means of a nested casecontrol study. The exposure history of each case of interest (death or incident cancer) was compared with that of four matching controls by means of conditional logistic regression. ${ }^{8}$ Controls were

Table 3 Cancer mortality 1958-88

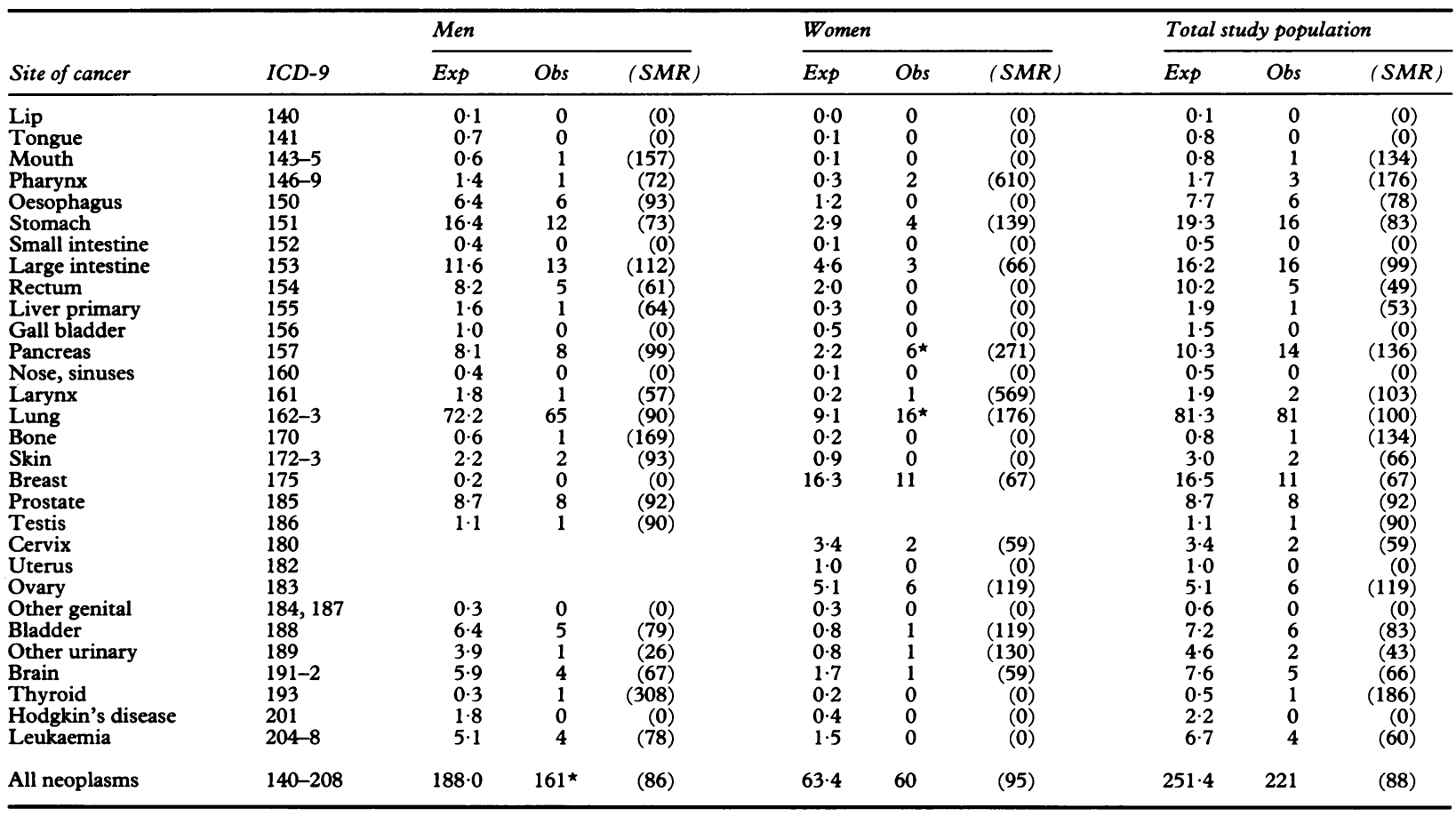

${ }^{\star} \mathrm{p}<0.05$. 
Table 4 Mortality from lung cancer and cancer of pancreas by type of cohort and by period from first employment, $1958-88$

\begin{tabular}{|c|c|c|c|c|c|c|c|c|c|c|c|c|}
\hline \multirow{3}{*}{$\begin{array}{l}\text { Years from } \\
\text { first } \\
\text { employment }\end{array}$} & \multicolumn{6}{|c|}{ Lung cancer } & \multicolumn{6}{|c|}{ Cancer of pancreas } \\
\hline & \multicolumn{2}{|c|}{$\begin{array}{l}\text { Survivor } \\
\text { population }\end{array}$} & \multicolumn{2}{|c|}{ Entry cohort } & \multicolumn{2}{|c|}{ Total } & \multicolumn{2}{|c|}{$\begin{array}{l}\text { Survivor } \\
\text { population }\end{array}$} & \multicolumn{2}{|c|}{ Entry cohort } & \multicolumn{2}{|c|}{ Total } \\
\hline & Obs & (SMR) & Obs & $(S M R)$ & Obs & (SMR) & Obs & $(S M R)$ & Obs & $(S M R)$ & Obs & (SMR) \\
\hline $\begin{array}{c}\text { Men: } \\
0-4 \\
5-9 \\
10-14 \\
\geqslant 15\end{array}$ & $\begin{array}{r}2 \\
4 \\
5 \\
29\end{array}$ & $\begin{array}{r}(176) \\
(108) \\
(75) \\
(83)\end{array}$ & $\begin{array}{l}2 \\
6 \\
9 \\
8\end{array}$ & $\begin{array}{r}(48) \\
(92) \\
(126) \\
(104)\end{array}$ & $\begin{array}{r}4 \\
10 \\
14 \\
37\end{array}$ & $\begin{array}{r}(76) \\
(98) \\
(101) \\
(86)\end{array}$ & $\begin{array}{l}0 \\
0 \\
0 \\
5\end{array}$ & $\begin{array}{r}(0) \\
(0) \\
(0) \\
(129)\end{array}$ & $\begin{array}{l}0 \\
0 \\
1 \\
2\end{array}$ & $\begin{array}{r}(0) \\
(0) \\
(117) \\
(215)\end{array}$ & $\begin{array}{l}0 \\
0 \\
1 \\
7\end{array}$ & $\begin{array}{r}(0) \\
(0) \\
(64) \\
(146)\end{array}$ \\
\hline Total & 40 & (86) & 25 & (98) & 65 & (90) & 5 & (98) & 3 & $(100)$ & 8 & (99) \\
\hline $\begin{array}{c}\text { Women: } \\
0-4 \\
5-9 \\
10-14 \\
\geqslant 15\end{array}$ & $\begin{array}{l}0 \\
0 \\
1 \\
4\end{array}$ & $\begin{array}{r}(0) \\
(0) \\
(127) \\
(125)\end{array}$ & $\begin{array}{l}1 \\
3 \\
2 \\
5\end{array}$ & $\begin{array}{l}(214) \\
(347) \\
(174) \\
(241)\end{array}$ & $\begin{array}{l}1 \\
3 \\
3 \\
9\end{array}$ & $\begin{array}{l}(168) \\
(233) \\
(155) \\
(170)\end{array}$ & $\begin{array}{l}0 \\
0 \\
0 \\
0\end{array}$ & $\begin{array}{l}(0) \\
(0) \\
(0) \\
(0)\end{array}$ & $\begin{array}{l}1 \\
2 \\
1 \\
2\end{array}$ & $\begin{array}{l}(857) \\
(954) \\
(361) \\
(406)\end{array}$ & $\begin{array}{l}1 \\
2 \\
1 \\
2\end{array}$ & $\begin{array}{l}(672) \\
(633) \\
(214) \\
(156)\end{array}$ \\
\hline Total & 5 & $(110)$ & 11 & $(241)$ & 16 & $(176)$ & 0 & $(0)$ & 6 & $(548)$ & 6 & $(271)$ \\
\hline
\end{tabular}

^Irrespective of how long any worker remains in employment.

chosen from other employees of the same sex employed at the case factory, and were matched closely on date of commencing employment and age at commencing employment. Potential controls had to be alive and free of the disease under investigation at the time the case event occurred (time measured from date of commencing employment). Any occupational exposures experienced by controls in later periods were ignored. The recorded job histories of all cases and controls were reviewed by occupational hygienists, blind to any knowledge of case or control state. Each period of employment was assessed for nine categories of occupational exposure.

\section{Results}

EXTERNAL STANDARD

Observed and expected numbers of deaths for mortality from all causes were calculated by year of death for men, women, and the total study population. An unusually low SMR was found for the earlier period, 1958-65 (total study population: Exp 20.7, Obs 8, SMR 39, 95\% CI 17-76).
Observed and expected numbers of deaths for mortality from all causes were calculated by factory. The overall SMR of 97 was within the $95 \%$ CI of each factory SMR. Observed and expected numbers of deaths for mortality from all causes were also calculated by years from first employment and by type of cohort. There was some evidence of a healthy worker effect with lower SMRs in the periods after first employment, although, in general, monotonic trends were not shown.

Table 3 shows the observed and expected numbers of deaths for mortality by site of cancer. Statistically significant deficits were found for all neoplasms among men (Exp 188.0, Obs 161, SMR 86, 95\% CI $73-100, p<0.05)$. Statistically significant excesses were found for cancer of the pancreas among women (Exp 2.2, Obs 6, SMR 271, 95\% CI 100-595, p < $0.05)$, and cancer of the lung among women $(\operatorname{Exp} 9 \cdot 1$, Obs 16, SMR 176, 95\% CI 100-285, p < 0.05). Given the numerous statistical tests carried out on these tables it is likely that some significant results are chance findings. For the total study population the SMR for cancer of the lung was $100(\operatorname{Exp} 81 \cdot 3$, Obs

Table 5 Mortality among total study population, 1958-88

\begin{tabular}{|c|c|c|c|c|}
\hline Cause of death & $I C D-9$ & $\operatorname{Exp}$ & Obs & $(S M R)$ \\
\hline $\begin{array}{l}\text { Neoplasms } \\
\text { Diseases of circulatory system } \\
\text { Diseases of respiratory system } \\
\text { Diseases of digestive system } \\
\text { Diseases of genitourinary system } \\
\text { Accidents } \\
\text { Suicide } \\
\text { All other causes }\end{array}$ & $\begin{array}{l}140-239 \\
390-459 \\
460-519 \\
520-579 \\
580-629 \\
800-949 \\
950-959\end{array}$ & $\begin{array}{r}251 \cdot 4 \\
385 \cdot 1 \\
77 \cdot 2 \\
23 \cdot 5 \\
8 \cdot 9 \\
32 \cdot 5 \\
16 \cdot 4 \\
48 \cdot 5\end{array}$ & $\begin{array}{c}221 \\
386 \\
82 \\
28 \\
7 \\
19^{\star} \\
16 \\
57 \dagger\end{array}$ & $\begin{array}{r}(88) \\
(100) \\
(106) \\
(119) \\
(79) \\
(58) \\
(98) \\
(118)\end{array}$ \\
\hline All causes & & 843.5 & 816 & $(97)$ \\
\hline
\end{tabular}

$* \mathrm{p}<0.05$

†Including 20 deaths cause not known. 
Table 6 Incidence of cancer among total study population, $1958-88$

\begin{tabular}{|c|c|c|c|c|}
\hline Site of cancer & $I C D-9$ & $\operatorname{Exp}$ & Obs & $(S R R)$ \\
\hline $\begin{array}{l}\text { Lip } \\
\text { Tongue } \\
\text { Salivary gland } \\
\text { Mouth } \\
\text { Pharynx } \\
\text { Oesophagus } \\
\text { Stomach } \\
\text { Small intestine } \\
\text { Large intestine } \\
\text { Rectum } \\
\text { Liver } \\
\text { Gall bladder } \\
\text { Pancreas } \\
\text { Peritoneum + other } \\
\text { dig. } \\
\text { Nose, sinuses } \\
\text { Larynx } \\
\text { Lung } \\
\text { Bone } \\
\text { Connective tissue } \\
\text { Malignant melanoma } \\
\text { Other skin } \\
\text { Breast } \\
\text { Cervix } \\
\text { Chorionephithelioma } \\
\text { Uterus } \\
\text { Ovary } \\
\text { Prostate } \\
\text { Testis } \\
\text { Other genital } \\
\text { Bladder } \\
\text { Kidney } \\
\text { Eye } \\
\text { Brain } \\
\text { Thyroid } \\
\text { Other endocrine } \\
\text { Unspecified } \\
\text { Lymphosarcoma } \\
\text { Hodgkin's disease } \\
\text { Multiple myeloma } \\
\text { Leukaemia } \\
\text { Mang }\end{array}$ & $\begin{array}{l}158-9 \\
160 \\
161 \\
162-3 \\
170 \\
171 \\
172 \\
173 \\
174,175 \\
180 \\
181 \\
179,182 \\
183 \\
185 \\
186 \\
184,187 \\
188 \\
189 \\
190 \\
191-2 \\
193 \\
194 \\
195-9 \\
200,202 \\
201 \\
203 \\
204-8\end{array}$ & $\begin{array}{r}0.9 \\
0.7 \\
3.9 \\
65.6 \\
0.8 \\
1.6 \\
4 \cdot 1 \\
31 \cdot 6 \\
24.3 \\
6 \cdot 1 \\
0.0 \\
3.9 \\
5.0 \\
11.0 \\
3.8 \\
1.4 \\
14.3 \\
5.4 \\
0.6 \\
6.6 \\
1.3 \\
0.4 \\
12.2 \\
6.6 \\
3.5 \\
2.6 \\
5.9\end{array}$ & $\begin{array}{r}0 \\
0 \\
7 \\
76 \\
0 \\
4 \\
2 \\
25 \\
23 \\
3 \\
0 \\
3 \\
6 \\
10 \\
3 \\
1 \\
9 \\
8 \\
1 \\
7 \\
1 \\
1 \\
11 \\
5 \\
2 \\
5 \\
4\end{array}$ & $\begin{array}{r}(0) \\
(0) \\
(178) \\
(116) \\
(0) \\
(255) \\
(49) \\
(79) \\
(95) \\
(49) \\
(0) \\
(77) \\
(121) \\
(91) \\
(79) \\
(71) \\
(63) \\
(149) \\
(167) \\
(106) \\
(78) \\
(257) \\
(90) \\
(75) \\
(57) \\
(193) \\
(68)\end{array}$ \\
\hline Total & $140-208$ & $294 \cdot 3$ & 277 & (94) \\
\hline
\end{tabular}

81) and that for cancer of the pancreas was 136 (Exp $10 \cdot 3$, Obs 14). Neither of these SMRs is significantly different from 100 . The extent to which regional variation in mortality may have influenced findings for cancers of the lung and pancreas was assessed by applying SMRs (1981) for relevant Regional Health Authorities as weighting factors to the expectations for each factory population. At this level, the influence of regional variation was marginal.

Table 4 shows observed and expected numbers of deaths for mortality from cancer of the lung by years from first employment and by type of cohort. Table 4 also shows data for cancer of the pancreas. Findings are not suggestive of occupational factors being involved.

Table 5 shows the observed and expected numbers of deaths for broad non-cancer disease groupings for the total study population. A statistically significant deficit is shown for accidents.

Table 6 shows the observed and expected numbers of cancer registrations for the period 1971-86 for the total study population. Similar tables were also generated for men and women separately and statistically significant excesses were found among women for: cancer of the pancreas (Exp 1.6, Obs 5, SRR 322, $95 \%$ CI 105-755, p $<0.05)$; cancer of the larynx (Exp 0.3, Obs 3, SRR 1024, 95\% CI 213$3024, p<0.01$ ); cancer of the lung (Exp 7.3, Obs 17, SRR 233, 95\% CI 136-373, p < 0.01); and cancer of the kidney (Exp 0.9, Obs 4, SRR 449, 95\% CI 122$1146, \mathrm{p}<0.05)$.

The SMRs for all sites of cancer considered (by others) to be related to cigarette smoking ${ }^{9}$ were compared with those for all other sites of cancer (see table 7). A striking difference was found for women, with all previously mentioned excesses appearing in the smoking related group. A survey of smoking habits among 1462 workers in the flexible polyurethane foam industry had been carried out in 1981 as part of the longitudinal survey of respiratory effects. ${ }^{6}$ Smoking histories had been obtained for 1059 men and 247 women (Clarke R L, personal communication); $58 \%$ of the women were current smokers $(n=142$, SE $3.2 \%)$, compared with $57 \%$ of the men $(n=594, S E 2 \cdot 1 \%)$. Corresponding figures for England and Wales (1980) obtained by the OPCS Social Survey Division were $42 \%$ and $37 \%$ for men and women respectively. ${ }^{10}$

\section{INTERNAL STANDARD}

On the basis of the results described, cancers of the lung and pancreas were selected as causes of death of primary interest for further study. Mortality from diseases of the respiratory system was selected for further investigation because of the known potential for respiratory tract irritation resulting from exposure to isocyanate. It is most unlikely that occupational isocyanate exposures could influence

Table 7 Mortality from smoking related cancers among total study population, 1958-88

\begin{tabular}{lccc}
\hline Subcohort & Exp & Obs & (SMR) \\
\hline \multicolumn{4}{c}{ Cancers related to cigarette smoking } \\
Men: & $65 \cdot 0$ & 53 & $(82)$ \\
Survivor population & $36 \cdot 6$ & 35 & $(96)$ \\
Entry cohort & & & \\
Women: & $7 \cdot 6$ & 7 & $(92)$ \\
Survivor population & $7 \cdot 6$ & $20^{\star \star \star}$ & $(263)$ \\
Entry cohort & & & \\
\multicolumn{1}{c}{ Cancers unrelated to cigarette smoking } & \\
Men: & $52 \cdot 7$ & 43 & $(82)$ \\
Survivor population & $33 \cdot 7$ & 30 & $(89)$ \\
Entry cohort & & & \\
Women: & $22 \cdot 8$ & 16 & $(70)$ \\
Survivor population & $25 \cdot 4$ & 17 & $(67)$ \\
Entry cohort & & & \\
\hline
\end{tabular}

$\star \star \star \mathrm{p}<0.001$

†Lung, tongue, mouth, pharynx, oesophagus, pancreas, larynx, bladder, other urinary (see ref 9 ). 
Table 8 Cancers of the lung and bronchus: distribution of deaths

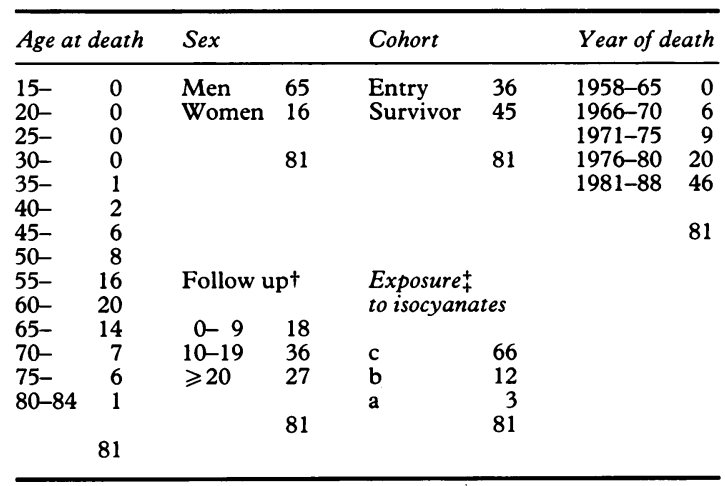

^Entry cohort or survivor population (see text).

†Period from first employment to death $(y)$.

$\mathrm{ta}=$ Ever higher, $\mathrm{b}=$ ever lower, $=\mathrm{c}$ always minimal $/$ zero or unclassifiable.

mortality in general, and mortality from all causes provided, therefore, a large neutral data set to assess the usefulness of the explanatory variables. Of secondary interest, incident cancers of the larynx and kidney were also selected for further study.

Table 8 shows numbers of deaths for mortality from cancer of the lung by levels of the explanatory variables. In constructing the models, careful attention was paid to the distribution of observed deaths, and where necessary, levels were combined to ensure that at least one death was observed in each level as entered into the analysis. Death rates for cancer of the lung were first modelled as a function of attained age (eight levels), sex, calendar year (four levels), and period of follow up (three levels). The introduction of type of cohort (two levels) made no improvement to the model and this variable was ignored. Table 9 displays the fitted (or theoretical) values produced by the model for all combinations of all levels of the explanatory values over three levels of period of follow up and the three exposure groupings. (Note that the exposure variable is not included in this model.) The inclusion of exposure to isocyanates made little difference to the overall model (change in deviance $0 \cdot 1$, change in degrees of freedom 2 ). This difference did not approach statistical significance and the relative risks associated with the exposure categories are not different from unity (see table 10). All of the female deaths from lung cancer occurred in the always minimal/zero exposure group.

For mortality from cancer of the pancreas, there were no observed deaths in the ever higher exposure group, and this group was, therefore, combined with the ever lower group. The inclusion of exposure to isocyanates made no difference to the overall model. The relative risk (point estimate) associated with ever lower or higher was close to unity (see table 10) and provided no evidence that exposure to isocyanates is a risk factor for cancer of the pancreas. Similar results were obtained when calendar year and follow up period were deleted from the model.

For mortality from diseases of the respiratory system, the inclusion of exposure to isocyanates did not make a statistically significant improvement to the overall model (change in deviance $2 \cdot 3$, change in degrees of freedom 2). Relative risks associated with the ever lower and ever higher exposure categories were 0.66 and 1.76 respectively (see table 10 ). The relative risk of 1.76 was based on only three deaths and was associated with a wide $95 \% \mathrm{CI}$.

Incident cancers of the larynx and kidney had been selected for further investigation. Examination of these cases indicated that all were members of the always minimal/zero exposure group, and it follows that any analysis of these data would not be capable of implicating exposure to isocyanates as a factor in the causation of these cases. Tabulations for these disease groupings, have, therefore, not been made.

Further investigation, in the form of a nested casecontrol study, was carried out for other occupational exposures and female cancers (deaths or incident cases) of the lung, pancreas, larynx, and kidney. Four controls were selected for each case of interest in the manner described previously. Case-control comparisons for unlagged exposures provided no statistically significant findings. The analyses were

Table 9 Cancers of the lung. Results of fitting multiplicative model with the factors: ${ }^{\star}$ attained age, calendar year, period of follow up and sex

\begin{tabular}{|c|c|c|c|c|}
\hline \multirow[b]{2}{*}{$\begin{array}{l}\text { Follow up } \\
(y)\end{array}$} & \multicolumn{4}{|c|}{ Level of exposure to isocyanates } \\
\hline & \multicolumn{2}{|c|}{$\begin{array}{l}\text { Always } \\
\text { minimal/zero }\end{array}$} & $\begin{array}{l}\text { Ever } \\
\text { lower }\end{array}$ & $\begin{array}{l}\text { Ever } \\
\text { higher }\end{array}$ \\
\hline \multicolumn{5}{|c|}{ Men } \\
\hline $0-9$ & $\mathrm{O}$ & $\begin{array}{l}11 \\
12 \cdot 12\end{array}$ & $\begin{array}{l}2 \\
2 \cdot 00\end{array}$ & $\begin{array}{l}1 \\
0 \cdot 42\end{array}$ \\
\hline $10-19$ & $\stackrel{\mathrm{O}}{\mathrm{F}}$ & $\begin{array}{l}21 \\
21 \cdot 61\end{array}$ & $\begin{array}{l}7 \\
5 \cdot 13\end{array}$ & $\begin{array}{l}1 \\
1 \cdot 08\end{array}$ \\
\hline$\geqslant 20$ & $\stackrel{\mathrm{O}}{\mathrm{F}}$ & $\begin{array}{l}18 \\
17 \cdot 11\end{array}$ & $\begin{array}{l}3 \\
4 \cdot 65\end{array}$ & $\begin{array}{l}1 \\
0 \cdot 89\end{array}$ \\
\hline Total & $\stackrel{\mathrm{O}}{\mathrm{F}}$ & $\begin{array}{l}50 \\
50 \cdot 84\end{array}$ & $\begin{array}{l}12 \\
11 \cdot 78\end{array}$ & $\begin{array}{l}3 \\
2 \cdot 38\end{array}$ \\
\hline \multicolumn{5}{|c|}{ Women } \\
\hline $0-9$ & $\stackrel{\mathrm{O}}{\mathrm{F}}$ & $\begin{array}{l}4 \\
3 \cdot 44\end{array}$ & $\begin{array}{l}0 \\
0 \cdot 03\end{array}$ & $\begin{array}{l}0 \\
0 \cdot 01\end{array}$ \\
\hline $10-19$ & $\mathrm{O}$ & $\begin{array}{l}7 \\
8 \cdot 10\end{array}$ & $\begin{array}{l}0 \\
0 \cdot 07\end{array}$ & $\begin{array}{l}0 \\
0 \cdot 01\end{array}$ \\
\hline$\geqslant 20$ & $\mathrm{O}$ & $\begin{array}{l}5 \\
4 \cdot 23\end{array}$ & $\begin{array}{l}0 \\
0 \cdot 11\end{array}$ & $\begin{array}{l}0 \\
0.02\end{array}$ \\
\hline Total & $\stackrel{\mathrm{O}}{\mathrm{F}}$ & $\begin{array}{l}16 \\
15 \cdot 77\end{array}$ & $\begin{array}{l}0 \\
0 \cdot 20\end{array}$ & $\begin{array}{l}0 \\
0.03\end{array}$ \\
\hline
\end{tabular}

$\mathrm{O}=$ Observed; $\mathrm{F}=$ fitted.

^Factors (with number of levels): sex (2), attained age (8), calendar year (4), and period of follow up (3). 
Table 10 Relative risks for level of exposure to isocyanates obtained from a multiplicative model and analysed jointly with the factors: attained age, calendar year, period of follow up and sex

\begin{tabular}{|c|c|c|}
\hline Level of exposure to isocyanates & $R R$ & $(95 \% C I)$ \\
\hline $\begin{array}{l}\text { All causes: } \\
\text { Minimal/zero } \\
\text { Ever lower } \\
\text { Ever higher }\end{array}$ & $\begin{array}{l}1 \cdot 0 \\
1.03 \\
0.55^{\star}\end{array}$ & $\begin{array}{l}(0.84-1.25) \\
(0.32-0.95)\end{array}$ \\
\hline $\begin{array}{l}\text { Cancer of lung: } \\
\text { Minimal/zero } \\
\text { Ever lower } \\
\text { Ever higher }\end{array}$ & $\begin{array}{l}1 \cdot 0 \\
1 \cdot 01 \\
1 \cdot 26\end{array}$ & $\begin{array}{l}(0.54-1.91) \\
(0.39-4.09)\end{array}$ \\
\hline $\begin{array}{l}\text { Cancer of pancreas: } \\
\text { Minimal/zero } \\
\text { Ever lower or higher }\end{array}$ & $\begin{array}{l}1 \cdot 0 \\
1 \cdot 10\end{array}$ & $(0 \cdot 23-5 \cdot 38)$ \\
\hline $\begin{array}{l}\text { Diseases of respiratory system: } \\
\text { Minimal/zero } \\
\text { Ever lower } \\
\text { Ever higher }\end{array}$ & $\begin{array}{l}1 \cdot 0 \\
0 \cdot 66 \\
1 \cdot 76\end{array}$ & $\begin{array}{l}(0.31-1.38) \\
(0.54-5.73)\end{array}$ \\
\hline
\end{tabular}

${ }^{\star} \mathrm{p}<0.05$.

repeated with all exposures lagged first by five years and then by 10 years, to take into account the likely latency intervals of any occupational cancers. Few cases or controls remained in the exposed categories, and all relative risks remained non-significant. Table 11 summarises the case-control comparisons for cancer of the lung, with exposures lagged by 10 years.

\section{Discussion}

Many of the factories that participated in the survey only began the manufacture of polyurethane foam in the 1970s, and the study was designed to supply more useful information in later analyses. The definition of the database is complex, in that for each factory there are different calendar year ranges for the survivor population and the entry cohort. Findings for the entry cohort are simpler to interpret, and in future analyses, more weight can be given to the findings for this subcohort.

No deaths (from any cause) occurred in female employees with any period of higher or lower exposure to diisocyanates, and it follows that this analysis is not capable of providing any evidence that these exposures played a part in the cancer excesses found in the SMR analysis. Other occupational exposures were also investigated, and although the numbers of cases were small for useful statistical analysis, findings were unexceptional. Furthermore, the distribution of the excesses of cancer by period from first employment suggested strongly that occupational factors in the industry were not important.

Some data on smoking habits were available from the United Kingdom longitudinal study of respiratory effects among workers in this industry.
Table 11 Cancers of the lung and bronchus among women: investigation of nine occupational exposures by means of nested case-control study ${ }^{\star}$ (exposures lagged by 10 years)

\begin{tabular}{llcl}
\hline Test factor & $\begin{array}{l}\text { Exposed } \dagger \\
\text { cases }\end{array}$ & $\begin{array}{l}\text { Exposed } \dagger \\
\text { controls }\end{array}$ & $\begin{array}{l}R R_{+}^{+} \\
(95 \% \mathrm{CI})\end{array}$ \\
\hline Amine catalysts & 0 & 3 & 0.0 \\
Non-flammable solvents & 0 & 3 & 0.0 \\
Flammable solvents & 2 & 9 & $0.9(0.2-4 \cdot 8)$ \\
Polyurethane dust & 3 & 11 & $1.2(0 \cdot 2-7 \cdot 0)$ \\
Latex & 2 & 8 & $1.0(0.0-22 \cdot 0)$ \\
Rubber & 1 & 4 & $1.0(0 \cdot 1-8 \cdot 9)$ \\
Curled hair/coir fibre & 0 & 0 & - \\
Feathers & 0 & 0 & - \\
Foam handling & 8 & 31 & $1 \cdot 1(0.3-3.9)$ \\
\hline
\end{tabular}

*Twenty cases (deaths or registrations) and 80 matched controls (four controls per case).

tKnown to be employed for one year or more in jobs involving potential for given occupational exposure.

$\ddagger$ Risk for employed one year or more in exposed jobs compared with not employed or employed less than one year in exposed jobs.

These data indicated that smoking habits among women may lead to raised SMRs at the sites of cancer under discussion. This factor alone, however, is unlikely to explain the whole of the excess, and chance may have a large part to play in some or all of the excesses found.

It will be important to compare these results with those of similar studies being carried out in Sweden and in the United States. It will also be important to monitor the health of this study population, and an analysis of a further five years of follow up (1989-93) will be carried out in 1995. Currently available data leads to the conclusion that the excesses of female cancer found in the SMR analysis are probably due to a combination of cigarette smoking, chance, and factors unrelated to the industry under study.

We thank the members of the project steering group for their advice and support. The group comprises Dr J A H Waterhouse (chair), Professor J M Harrington, Dr J K Straughan, Dr J Osman, Mr A R Nutt, Mr D S Gilbert, Mr K J Watson, Dr D C Allport, Dr R Owen, Dr P Davies, and Dr G M Paddle. We thank Dr R D Jones and Dr F G Rose for their earlier involvement. A key part was played by Mr J Bugler who carried out the isocyanate exposure assessments, and we also thank Mr A R Nutt for assistance with coding other occupational exposures. We thank Pat Boyd, Margaret Nutt, Christine Briggs and Alan Menzies for data collection, the Office of Population Censuses and Surveys for tracing the study population, Alison Taylor for word processing, and the management and workforce of the industry concerned for supporting the project.

1 Health and Safety Executive. Isocyanates, toxic hazards and precautions. London: Health and Safety Executive, 1984. (Guidance note $\mathrm{EH} 16,1984$.)

2 Weill DH, Salvaggio J, Neilson A, Butcher B, Ziskind M. Respiratory effects in toluene di-isocyanate manufacture; a 
multidisciplinary approach. Environ Health Perspect 1975;11: 101-8.

3 Adams WGF. Long term effects on the health of men engaged in the manufacture of tolylene di-isocyanate. $\mathrm{Br} J$ Ind Med 1975; 32:72-8.

4 Wegman DH, Peters JM, Pagnotto LD, Fine LJ. Chronic pulmonary function loss from exposure to toluene di-isocyanate. Br J Ind Med 1977;34:196-200.

5 Weyel DA, Schaffer RB. Pulmonary and sensory irritation of diphenylmethane- $4,4^{\prime}$ and dicyclohexymethane-4, $4^{\prime}$ diisocyanate. Toxicol Appl Pharmacol 1985;77:427-33.

6 Clarke R, Parkes HG, Nutt A, Elmes PC, Cotes JE, McDermott $M$, Berry $G$. A protocol for the investigation of acute and long term respiratory effects of organic isocyanates. London: Medical Research Council, UK, July 1977.
7 Breslow NE, Day NE. Statistical methods in cancer research. Vol II-The design and analysis of cohort studies. Lyon: International Agency for Research on Cancer, 1987. (IARC sci pub No 82.)

8 Breslow NE, Day NE. Statistical methods in cancer research. Vol I-The design and analysis of cohort studies. Lyon: International Agency for Research on Cancer, 1980. (IARC sci pub No 32.)

9 International Agency for Research on Cancer. IARC monographs on the evaluation of the carcinogenic risk of chemicals to humans. Vol 38. Tobacco smoking. Lyon: IARC, 1986.

10 General Household Survey 1988. OPCS Social Survey Division. London: HMSO, 1989. (Series GHS No 19.)

Accepted 6 July 1992 